\title{
TINJAUAN ANALISIS PERHITUNGAN KEBUTUHAN AIR BERSIH DAN AIR LIMBAH UNTUK PERENCANAAN SISTEM PENYALURAN AIR LIMBAH DI PERUMAHAN BUMI CIRUAS PERMAI 1 KABUPATEN SERANG
}

\author{
Frebhika Sri Puji Pangesti ${ }^{1}$, Ade Ariesmayana ${ }^{2}$ \\ Program Studi Teknik Lingkungan, Universitas Banten Jaya, Jl. Raya Ciwaru II No.73 Kota Serang, Banten
}

Email: frebhikasripujipangesti@unbaja.ac.id

Email: adeariesmayana@unbaja.ac.id

\begin{abstract}
ABSTRAK
Perumahan Bumi Ciruas Permai I terletak di Kecamatan Ciruas Kabupaten Serang. Kawasan ini mempunyai luas sebesar $253.839 \mathrm{~m}^{2}$ dan jumlah populasi penduduknya sebesar 1352 jiwa. Jumlah penduduk dari tahun ke tahun semakin meningkat, dengan peningkatan jumlah penduduk tersebut berakibat kebutuhan air bersih dan air limbah yang ada di Perumahan Bumi Ciruas Permai I juga mengalami peningkatan. Wilayah perumahan Bumi Ciruas Permai I berdasarkan area beresiko sanitasi termasuk kedalam kategori sanitasi sangat tinggi. Greywater yang dihasilkan langsung dibuang ke saluran drainase tanpa pengolahan, sedangkan sisa air buangan (black water) yang mengandung urine dan tinja akan ditampung ke dalam tangki septic. Upaya meminimalisir pencemaran diperlukan perencanaan sistem penyaluran air limbah dengan sistem terpusat, sehingga diperlukan peninjauan tingkat kebutuhan air bersih dan air limbah pada wilayah tersebut.Metode perencanaan dengan memproyeksikan jumlah penduduk sampai dengan tahun 2029 dengan menggunakan tiga metode yaitu aritmatik,geometrik, dan eksponensial, serta menghitung proyeksi kebutuhan air bersih di wilayah perencanaan.Berdasarkan hasil perhitungan didapatkan total kebutuhan air bersih domestik dan kebutuhan air non domestik (fasilitas umum) pada Perumahan Bumi Ciruas Permai I tahun 2029 sebesar 316.546 liter/hari.Debit air limbah masyarakat Perumahan Bumi Ciruas Permai I sebesar 253,237 $\mathrm{m}^{3} /$ hari, sedangkan debit air limbah grey water sebesar $189,92 \mathrm{~m}^{3} /$ hari. Hasil perhitungan tersebut akan dijadikan dasar dalam perencanaan sistem penyaluran air limbah sesuai dengan Peraturan Menteri Pekerjaan Umum dan Perumahan Rakyat No. 4 Tahun 2017 Tentang Penyelenggaran Sistem Pengelolaan Air Limbah Domestik (SPALD).
\end{abstract}

Kata kunci: SPALD, Air Bersih, Domestik

\section{PENDAHULUAN}

Seiring dengan bertambahnya jumlah penduduk, kebutuhan air bersih akan semakin meningkat.Peningkatan jumlah kebutuhan air bersih akan diiringi dengan bertambahnya kuantitas air limbah yang dihasilkan. Air limbah merupakan air buangan yang berasal dari rumah tangga, industri maupun tempat umum lainnya yang apabila tidak dikelola akan berdampak buruk bagi kesehatan dan lingkungan..Perumahan Bumi Ciruas Permai merupakan salah satu perumahan yang terletak pada Kecamatan Ciruas Kabupaten Serang dengan luas $253.839 \mathrm{~m}^{2}$ dan jumlah penduduk sebesar 1352 jiwa. Sebagian besar masyarakat Perumahan Bumi Ciruas Permai telah memiliki jamban, dan sisa air buangan (black water) yang mengandung urine dan tinja akan ditampung ke dalam tangki septic. Sementara air buangan sisa limbah rumah tangga (grey water) seperti pada aktivitas mandi, mencuci dan lain-lain akan dialirkan melalui saluran kecil menuju saluran drainase. Pembuangan air limbah tanpa melalui proses pengolahan akan mengakibatkan terjadinya pencemaran lingkungan yang dapat mengganggu kesehatan masyarakat, penurunan daya tampung lingkungan. Berdasarkan observasi di lapangan jarak antar rumah pada perumahan Bumi Ciruas Permai sangat berdekatan satu sama lain,sehingga berpotensi terjadinya pencemaran air tanah. Dalam rangka mengatasi permasalahan tersebut diperlukan sistem penyaluran air limbah secara terpusat agar air limbah dapat terkelola dengan baik, Dalam penelitian ini akan merencanakan desain sistem penyaluran air limbah dengan off site system (terpusat).Sebelum merencanakan sistem penyaluran air limbah diperlukan melakukan perghitungan debit air limbah,perhitungan proyeksi penduduk,peninjauan tingkat kebutuhan air bersih dan air limbah yang dihasilkan di wilayah perencanaan, serta desain Sistem Jaringan Penyaluran Air Limbah domestic. 


\section{METODOLOGI PENELITIAN}

\subsection{Tahapan Pengumpulan Data}

Tahapan pengumpulan data merupakan langkah awal mencari data primer dan data sekunder.Data primer diperoleh dari observasi yang dilakukan terhadap kondisi eksisting di daerah perencanaan. Data Sekunder berupa data kependudukan, data kebutuhan air bersih, peta administrasi.

\subsection{Tahap Pengolahan dan Analisis Data}

\subsubsection{Proyeksi Penduduk}

a.

Menghitung proyeksi penduduk dalam 10 tahun yang akan datang dengan metode sebagai berikut;

1. Aritmatik

Metode aritmatika didasarkan pada anggapan bahwa laju perubahan populasi konstan, menggunakan asumsi bahwa pertumbuhan penduduk dengan jumlah sama setiap tahun. (Asep Suheri, 2019).Sumber (Asep Suheri, 2019).

Dimana:

$$
\mathrm{Pn}=\mathrm{Po}(1+\mathrm{r} . \mathrm{n})
$$

$$
\begin{array}{ll}
\mathrm{Pn} & =\text { Jumlah penduduk pada akhir tahun periode } \\
\mathrm{Po} & =\text { Jumlah penduduk pada awal proyeksi } \\
\mathrm{r} & =\text { Rata-rata pertumbuhan penduduk tiap tahun } \\
\mathrm{n} & =\text { Kurun waktu proyeksi }
\end{array}
$$

2. Geometrik

Proyeksi penduduk dengan metode geometrik menggunakan asumsi bahwa jumlah penduduk akan bertambah secara geometrik menggunakan dasar perhitungan bunga majemuk. (Michael Rinaldi, 2019).

$$
\mathrm{Pn}=\mathrm{Po}(1+\mathrm{r})^{\mathrm{n}}
$$

Dimana:

Pn = Jumlah penduduk pada tahun ke-n

Po = Jumlah penduduk pada tahun pertama/dasar

$\mathrm{r} \quad=$ Laju pertumbuhan penduduk

$\mathrm{n} \quad=$ Kurun waktu

3. Eksponensial

Metode eksponensial menggambarkan pertambahan penduduk yang terjadi secara sedikitsedikit sepanjang tahun. (Adioetomo dan Samosir, 2010)

$$
\mathrm{Pt}=\mathrm{Po}{ }^{*} \mathrm{e}^{\wedge} . \mathrm{n}
$$

Dimana:

$\begin{array}{ll}\mathrm{Pn} & =\text { Jumlah penduduk tahun akhir proyeksi } \\ \mathrm{Po} & =\text { Jumlah penduduk tahun awal terakhir } \\ \mathrm{r} & =\text { Rata-rata persentase tambahan penduduk pertahun } \\ \mathrm{n} & =\text { Kurun waktu } \\ \mathrm{e} & =\text { Bilangan pokok dari sistem logaritma }(2,7182818)\end{array}$


2.2.2.

Menghitung kebutuhan air bersih

Untuk menghitung kebutuhan air bersih maka diperlukan data jumlah penduduk lalu dikalikan dengan standar kebutuhan air bersih per liter per orang per hari sebesar 144 liter/hari. (Dirjen Cipta Karya, 2006).

Kebutuhan air bersih domestik

$$
\mathrm{Q}_{\mathrm{ave}}=\operatorname{Pn} \times \mathrm{q}
$$

Dimana:

Q ${ }_{\text {ave }} \quad=$ Kebutuhan air bersih (liter/hari)

Pn = Jumlah penduduk pada tahun $\mathrm{n}$ (orang)

$\mathrm{q} \quad=$ Kebutuhan air bersih (liter/orang/hari)

2.2.3.

Kebutuhan air bersih non domestik

Dimana:

$$
\mathrm{Q}_{\mathrm{fave}}=\operatorname{Pf} \mathrm{x} \mathrm{Q} \text { x Asumsi jumlah pemakai }
$$

$\mathrm{Q}_{\text {fave }} \quad=$ Kebutuhan air bersih (liter/hari)

Pf $\quad=$ Fasilitas umum

Ap = Asumsi Pemakaian (orang/unit)

$\mathrm{Q} \quad=$ debit (liter/orang/hari)

2.2.4.

Menghitung debit air limbah

Untuk menghitung debit air limbah diperlukan data berupa jumlah kebutuhan air bersih yang dikalikan dengan $80 \%$

Dimana:

$$
\mathrm{Q}_{\mathrm{d}}=\frac{80}{100} \times \sum \mathrm{Q}_{\mathrm{ave}}
$$

$\mathrm{Q}_{\mathrm{d}} \quad=$ Debit air limbah (liter/hari)

$\sum Q_{\text {ave }}=$ Kebutuhan air bersih (liter/hati)

\section{DATA DAN ANALISA}

3.1. Perhitungan Proyeksi Penduduk

Perhitungan proyeksi penduduk direncanakan 10 tahun ke depan dari tahun 2019-2029. Tabel berikut menunjukkan hasil perbandingan persentase pertumbuhan penduduk (r) dengan metode aritmatik, metode geometrik dan metode eksponensial.

Tabel 1 Perbandingan Rata-Rata Pertumbuhan Penduduk Masing-Masing Metode dengan Data Aktual

\begin{tabular}{llll}
\hline No & Metode & r & Nilai Aktual \\
\hline 1 & Aritmatik & $0,0180 / 1,80 \%$ & $0,0174 / 1,74 \%$ \\
2 & Geometrik & $0,0174 / 1,74 \%$ & $0,0174 / 1,74 \%$ \\
3 & Eksponensial & $0,0173 / 1,73 \%$ & $0,0174 / 1,74 \%$ \\
\hline
\end{tabular}

Sumber : Perhitungan Pertumbuhan Penduduk 
Journal JOSCE Vol.04 No.01 Februari 2022

Tabel 2 Proyeksi Penduduk 10 Tahun yang Akan Datang

\begin{tabular}{llllll}
\hline No & Tahun & Po & r & n & Pn \\
\hline 1 & 2020 & 1375 & 0,0174 & 1 & 1399 \\
2 & 2021 & 1375 & 0,0174 & 2 & 1423 \\
3 & 2022 & 1375 & 0,0174 & 3 & 1448 \\
4 & 2023 & 1375 & 0,0174 & 4 & 1473 \\
5 & 2024 & 1375 & 0,0174 & 5 & 1499 \\
6 & 2025 & 1375 & 0,0174 & 6 & 1525 \\
7 & 2026 & 1375 & 0,0174 & 7 & 1551 \\
8 & 2027 & 1375 & 0,0174 & 8 & 1578 \\
9 & 2028 & 1375 & 0,0174 & 9 & 1606 \\
10 & 2029 & 1375 & 0,0174 & 10 & 1634 \\
\hline
\end{tabular}

Sumber: Perhitungan Pertumbuhan Penduduk di Perumahan BCP, 2020

\subsection{Perhitungan Kebutuhan Air Bersih}

Untuk menghitung kebutuhan air bersih yang berada di Perumahan Bumi Ciruas Permai 1 selama 10 tahun yang akan datang, maka diperlukan data jumlah penduduk lalu dikalikan dengan standar kebutuhan air bersih per liter per orang per hari sebesar 144 liter/hari. (Dirjen Cipta Karya, 2006). Sementara untuk kebutuhan air bersih non domestik menggunakan standar SK-SNI Air Minum (2000). Timbulan air limbah domestik dapat diperoleh berdasarkan data pemakaian air minum, dengan menggunakan dasar perencanaan timbulan air limbah domestik berkisar 60 - 80\% pemakaian air minum.

1. Kebutuhan Air Bersih Domestik

Menghitung kebutuhan air bersih domestik dapat menggunakan rumus sebagai berikut:

$$
\begin{aligned}
\text { Qave } & =\text { Pn x q } \\
& =1634 \text { jiwa } \times 144 \text { liter/hari } \\
& =235.296 \text { liter/orang/hari } \\
& =\frac{235.296 \text { liter }}{86.400 \text { detik }} \\
& =2,7233 \text { liter/detik }
\end{aligned}
$$

2. Kebutuhan Air Bersih Non Domestik

Perumahan bumi ciruas permai 1 dilengkapi dengan fasilitas-fasilitas pendukung seperti 3 sarana kesehatan (puskesmas), 9 tempat peribadatan (masjid) dan 5 sekolah. Tabel kebutuhan air bersih non domestik dapat dilihat pada Tabel 3

Tabel 3 Kebutuhan Air Bersih Non Domestik

\begin{tabular}{cccccc}
\hline No & $\begin{array}{c}\text { Jenis } \\
\text { Fasilitas }\end{array}$ & $\begin{array}{c}\text { Jumlah } \\
\text { Fasilitas }\end{array}$ & $\begin{array}{c}\text { Debit } \\
\text { (liter/orang/ha } \\
\text { ri) }\end{array}$ & $\begin{array}{c}\text { Asumsi pemakai (SK- } \\
\text { SNI Air Minum) } \\
\text { (liter/hari) }\end{array}$ & $\begin{array}{c}\text { Kebutuhan air } \\
\text { (liter/unit/hari) }\end{array}$ \\
\hline 1 & Puskesmas & 3 & 25 & 30 & 2.250 \\
2 & Masjid & 9 & 30 & 200 & 54.000 \\
3 & Sekolah & 5 & 20 & 250 & 25.000 \\
& & & Jumlah Qfave & & $\mathbf{8 1 . 2 5 0}$ \\
\hline
\end{tabular}

Sumber: Perhitungan Kebutuhan Air Bersih di Perumahan BCP, 2020

Maka total kebutuhan air bersih di Perumahan Bumi Ciruas Permai 1 adalah sebagai berikut:

$\begin{array}{ll}\sum \text { Qave } & =\text { Qave }+\sum \text { Qfave } \\ \sum \text { Qave } & =235.296+81.250\end{array}$ 
QQave $\quad=316.546$ liter $/$ hari

¿Qave $\quad=\frac{316.546 \text { liter }}{86.400 \text { detik }}$

¿Qave $\quad=3,6637$ liter $/$ detik

Tabel 4 Total Kebutuhan Air Bersih

\begin{tabular}{cccc}
\hline No & $\begin{array}{c}\text { Kebutuhan air bersih } \\
\text { domestik } \\
\text { (liter/hari) }\end{array}$ & $\begin{array}{r}\text { Kebutuhan air bersih non } \\
\text { domestik (liter/hari) }\end{array}$ & $\begin{array}{c}\text { Total kebutuhan air } \\
\text { bersih (liter/hari) }\end{array}$ \\
\hline 1 & 235.296 & 81.250 & 316.546 \\
\hline
\end{tabular}

Sumber: Perhitungan Kebutuhan Air Bersih di Perumahan BCP, 2020

3.3. Perhitungan Debit Air Limbah

1. Debit Air Limbah

Timbulan air limbah domestik dapat diperoleh berdasarkan data pemakaian air minum, dengan menggunakan dasar perencanaan timbulan air limbah domestik berkisar 60 - 80\% pemakaian air minum.

$$
\begin{aligned}
\mathrm{Q}_{\mathrm{d}} & =\frac{80}{100} \times \sum \mathrm{Q}_{\mathrm{ave}} \\
\mathrm{Q}_{\mathrm{d}} & =\frac{80}{100} \times 316.546 \\
\mathrm{Q}_{\mathrm{d}} & =253.237 \text { liter/hari } \\
\mathrm{Q}_{\mathrm{d}} & =\frac{253.237 \text { liter }}{86.400 \text { detik }} \\
\mathrm{Q}_{\mathrm{d}} & =2,9309 \text { liter/detik }
\end{aligned}
$$

2. Q peak

$\mathrm{Q}$ peak $=\mathrm{Q}_{\mathrm{d}} \mathrm{x}$ faktor peak

$\mathrm{Q}$ peak $=2,9309$ liter/detik x 1,5 (SNI, Ditjen Cipta Karya)

$\mathrm{Q}$ peak $=4,3963$ liter/detik

3. Q infiltrasi

Luas area di Perumahan Bumi Ciruas Permai 1 sebesar $253.839 \mathrm{~m}^{2}$ atau 25,3839 Ha. Sementara untuk $\mathrm{f}$ infiltrasi didapatkan dari grafik average infiltration rate allowance.

Q infiltrasi

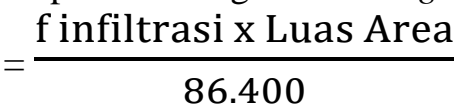

Q infiltrasi

$$
=\frac{8,9 \times 25,3839}{86.400}
$$

Q infiltrasi

$$
=\frac{225,91671}{86400}
$$

Q infiltrasi

$$
=0,0026 \text { liter/detik }
$$

4. Q total

Debit total $($ Qtotal $)=$ Qpeak + Qinf

$$
=4,3963 \text { liter } / \text { detik }+0,0026
$$

$=4,3989$ liter $/$ detik 
Journal JOSCE Vol.04 No.01 Februari 2022

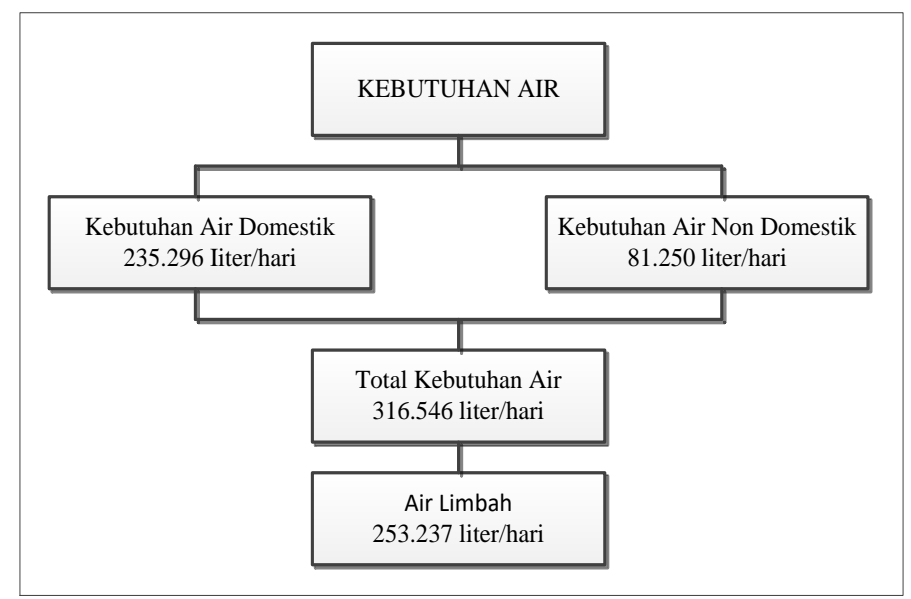

Gambar 1 Diagram Alir Kebutuhan Air

\subsection{Kuantitas Air Limbah}

Kuantitas air limbah domestik didasarkan dari data jumlah penduduk masyarakat Perumahan Bumi Ciruas Permai 1 yang dikalikan dengan standar kebutuhan air bersih per liter per orang per hari sebesar 144 liter/hari. (Dirjen Cipta Karya, 2006). Hasil dari pengumpulan data kuantitas air bersih didapatkan total kebutuhan air bersih sebesar 316.546 liter/hari. Pada perencanaan diterapkan 80\% merupakan angka persentase untuk menentukan air limbah dari penggunaan air bersih masyarakat Perumahan Bumi Ciruas Permai 1. Hal ini disesuaikan dengan literatur bahwa debit air limbah dapat perkirakan mencapai $80 \%$ kebutuhan air bersih pada perumahan. Untuk limbah grey water diperkirakan 50-80\% dari total air limbah perumahan. Oleh karena itu dalam perencanaan diterapkan $75 \%$ limbah grey water dari total air limbah domestik. Di peroleh total debit air limbah grey water masyarakat Perumahan Bumi Ciruas Permai 1 sebagai berikut:

$$
\begin{aligned}
& \text { Q limbah }\left(\mathrm{m}^{3} / \text { hari }\right) \quad=\frac{80}{100} \times \sum \mathrm{Q} \text { limbah total } \\
& =\frac{80}{100} \times 316.546 \text { liter } / \text { hari } \\
& =253.237 \text { liter/hari } \\
& =\frac{253.237 \text { liter } / \text { hari }}{1000} \\
& =253,237 \mathrm{~m}^{3} / \text { hari } \\
& \text { Q limbah tiap orang }\left(\mathrm{m}^{3} / \text { hari }\right)=\frac{\mathrm{Q} \operatorname{limbah}\left(\frac{\mathrm{m}^{3}}{\text { hari }}\right)}{\text { jumlah penduduk }} \\
& =\frac{253,237\left(\frac{\mathrm{m}^{3}}{\text { hari }}\right)}{1634 \text { jiwa }} \\
& =0,1549 \mathrm{~m}^{3} / \text { orang.hari } \\
& =154,9 \text { liter/orang.hari } \\
& =\frac{75}{100} \times \sum \text { Q limbah total } \\
& =\frac{75}{100} \times 253,237 \mathrm{~m}^{3} / \text { hari } \\
& =189,92 \mathrm{~m}^{3} / \text { hari }
\end{aligned}
$$

Dalam perhitungan diatas didapatkan nilai air limbah grey water sebesar 189,92 $\mathrm{m}^{3} / \mathrm{hari}$. Data debit air limbah ini yang nantinya akan digunakan dalam perencanaan unit pengolahan. 


\subsection{Perhitungan Prediksi Air Limbah}

Prediksi air limbah selama 10 tahun akan datang di Perumahan Bumi Ciruas Permai 1 dapat dilihat pada Tabel 5.

Tabel 5 Prediksi Air Limbah

\begin{tabular}{lllll}
\hline No & Tahun & $\begin{array}{l}\text { Jumlah } \\
\text { Penduduk }\end{array}$ & $\begin{array}{l}\text { Kebutuhan Air } \\
\text { Bersih } \\
\text { (liter/detik) }\end{array}$ & $\begin{array}{l}\text { Air Limbah } \\
\text { (liter/detik) }\end{array}$ \\
\hline 1 & 2014 & 1262 & 2,103 & 1,683 \\
2 & 2015 & 1283 & 2,138 & 1,711 \\
3 & 2016 & 1306 & 2,177 & 1,741 \\
4 & 2017 & 1328 & 2,213 & 1,771 \\
5 & 2018 & 1352 & 2,253 & 1,803 \\
6 & 2019 & 1375 & 2,292 & 1,833 \\
7 & 2020 & 1399 & 2,332 & 1,865 \\
8 & 2021 & 1423 & 2,371 & 1,897 \\
9 & 2022 & 1448 & 2,413 & 1,930 \\
10 & 2023 & 1473 & 2,455 & 1,964 \\
11 & 2024 & 1499 & 2,498 & 1,998 \\
12 & 2025 & 1525 & 2,542 & 2,034 \\
13 & 2026 & 1551 & 2,585 & 2,068 \\
14 & 2027 & 1578 & 2,63 & 2,104 \\
15 & 2028 & 1606 & 2,677 & 2,142 \\
16 & 2029 & 1634 & 2,723 & 2,178 \\
\hline
\end{tabular}

Sumber: Perhitungan Air Limbah di Perumahan BCP, 2020

\subsection{Desain Sistem Jaringan Penyaluran Air Limbah Domestik}

Sistem penyaluran air limbah domestik di Perumahan Bumi Ciruas Permai direncanakan menggunakan sistem terpusat (off site) dengan separate system, dimana air limbah domestik dan air hujan akan dialirkan secara terpisah (Marhadi,2016). Perencanaan saluran air buangan dilakukan dengan mempertimbangkan kepadatan penduduk dan volume air limbah yang dihasilkan dari aktifitas pemukiman. Berdasarkan hasil perhitungan proyeksi jumlah penduduk pada masa yang akan datang, wilayah perencanaan termasuk wilayah padat penduduk dan rentan terjadi pencemaran air tanah. Sistem pengaliran air limbah diusahakan secara gravitasi dan mengikuti jalan dan memperhatikan kontur. Layout perumahan Bumi Ciruas Permai dapat dilihat pada gambar 2. 


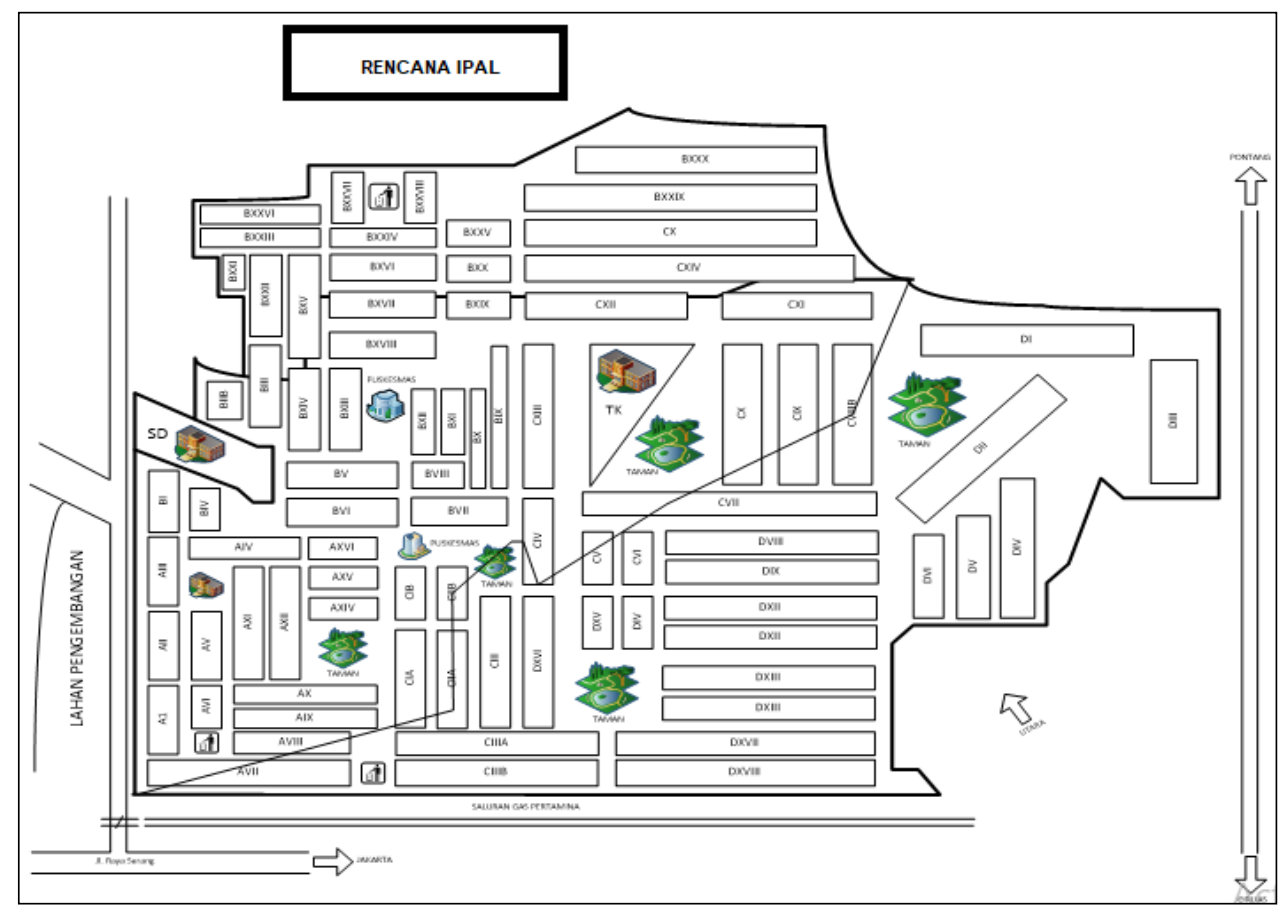

Gambar 2 Layout Perumahan Bumi Ciruas Permai

\section{KESIMPULAN}

Berdasarkan analisis dan perhitungan, maka dapat disimpulkan sebagai berikut :

1. Proyeksi jumlah penduduk Perumahan Bumi Ciruas Permai I pada tahun 2029 sebesar 1634 jiwa.

2. Total Kebutuhan air bersih domestik dan kebutuhan air non domestik (fasilitas umum) pada Perumahan Bumi Ciruas Permai I tahun 2029 sebesar 316.546 liter/hari.

3. Total debit air limbah masyarakat Perumahan Bumi Ciruas Permai I sebesar $253,237 \mathrm{~m}^{3} / \mathrm{hari}$, sedangkan debit air limbah grey water sebesar $189,92 \mathrm{~m}^{3} /$ hari.

\section{UCAPAN TERIMAKASIH}

Alhamdulillah puji syukur kepada Allah SWT, karena kehendak dan ridha-Nya penulis dapat menyelesaikan penelitian ini. Penulis menyadari ini tidak akan selesai tanpa doa, dukungan dan dorongan dari berbagai pihak

\section{DAFTAR PUSTAKA}

1. Asep Suheri. (2019). Model Prediksi Kebutuhan Air Bersih Berdasarkan Jumlah Penduduk di Kawasan Perkotaan Sentul City. Jurnal Teknik Sipil dan Lingkungan. Vol.4. No.01. 38.

2. Adioetomo, S. M. dan Samosir, O. B., (2010). Dasar-dasar Demografi Edisi 2. Jakarta: Salemba Empat.

3. Direktorat Jendral Cipta Karya Kementrian Pekerjaan Umum. (2006). Kriteria Penyediaan Air Bersih. Jakarta.

4. Marhadi.(2016). Analisis Sistem Penyaluran Air Buangan Domestik dengan Off Site System (Studi Kasus Kecamatan Jambi Timur Kota Jambi).Fakultas Teknik Universitas Batanghari.Jambi.

5. Pemerintah Indonesia. (2016). Kementerian Pekerjaan Umum Dan Pekerjaan Rakyat tentang Air Limbah Domestik. Jakarta: Sekretarian Negara. 
Journal JOSCE Vol.04 No.01 Februari 2022

6. Peraturan Menteri Pekerjaan Umum dan Perumahan Rakyat No. 4 Tahun 2017 tentang Penyelenggaran Sistem Pengelolaan Air Limbah Domestik (SPALD). 